\title{
User-Generated Contents in Facebook, Functional and Hedonic Brand Image and Purchase Intention
}

\author{
Raji Ridwan Adetunji ${ }^{1,}{ }^{*}$, Mohd Rashid Sabrina ${ }^{1}$, and Ishak Mohd Sobhi ${ }^{1}$ \\ ${ }^{1}$ Department of Media Management, School of Multimedia Technology and Communication, \\ Universiti Utara Malaysia, Malaysia.
}

\begin{abstract}
User-Generated Contents is a type of brand-related communications on social media platforms. User-Generated Contents (UGC) offers consumers the opportunity of sharing their experiences, contribute their opinion and communicate with other. This implies that brand managers no longer have solitary control in managing the brand images of their brands. Therefore, this study set out to examine the effect of user-generated contents on hedonic brand image and functional brand. Also, the study determines how hedonic and functional brand image influence brand purchase intention. 114 followers of fan pages of Malaysian automotive brands were surveyed. The hypotheses formulated were tested using PLS-SEM. The findings revealed that, UGC have significant and positive impact on both functional and hedonic brand image. Furthermore, functional and hedonic brand image have significant impact on purchase intention. This study provides insight on the importance of UGC, functional and hedonic brand image to brand managers.
\end{abstract}

\section{INTRODUCTION}

Social media including Facebook has become an important outlet for building and maintaining successful brand image [1]. Through fan pages or brand profiles that are created on social media, brand managers are offered limitless opportunities to share and post information in form of photos, videos, messages and comments about their brands and companies [2]. Meanwhile, the advent of social media as a channel for disseminating marketing communication messages has given birth to a new type of brand-related communication namely; UGCs which are posted on social media by consumers. Thus, User-Generated Contents on social media platforms allow consumers to share their experiences, contribute an opinion and communicate with other teeming numbers of consumers. This implies that brand managers no longer have solitary control of brand images of their brands [2]. However, this development has generated series of academic concerns which include measuring and understanding how the UGC opportunity alters firm's control of brand equity management [4]. Extant literatures have attempted to

\footnotetext{
* Corresponding author: rajiridwanadetunji@gmail.com
} 
examine the importance of social media on brand equity. Meanwhile few studies have examined the impact of UGC on functional and hedonic brand image. Furthermore, there is a scarce of empirical justifications on the impact of brand image on brand purchase intention [1].

\section{Literature review}

\subsection{User-generated contents}

UGCs are the types of social media contents that are created about a brand by consumers for other consumers' consumption [2]. This is possible because social media offers consumers the opportunity to publish and share self-generated contents between multitude of friends and followers. The possibility of generating and sharing contents about brands, affirms the active and influential role of consumers in managing brands on social media [5]. [6], asserted that before any content can be considered as UGC, it must bear one or all the following three features. Firstly, it must be accessible by the public through any of the social networking sites (such as Facebook, Twitter, Blog and YouTube). Secondly, the content must be created and published with certain amount of creativity, using animations, images, graphics, fictional or fictitious words. Finally, it must be created solely by individuals that are not working for any professional or corporate bodies.

\subsection{Functional and Hedonic Brand Image}

Bruhn and Schoenmueller [1] reviewed that; brand image signifies consumers' associations with a brand. These associations can be divided into two types namely; functional and hedonic brand image. Hedonic brand image can be explained as the perceptions, feelings, or meaning that consumers created from abstract and imagery-related considerations that are not necessarily related to the brand attributes, performance or utilitarian [7,1]. On the other hand, functional brand image illustrate that consumers' associations with brands serves as informational nodes that are connected to brand nodes in the consumers' mindset and these formulate meaningful information about the quality and value of the brand [8].

\subsection{Brand purchase intention}

Brand purchase intention is a major concern and the reason why brand managers exert aggressive measures to develop their brand assets such brand equity [9]. Building an attractive brand equity and brand image is absolutely necessary as a strategy for maintaining consumers' satisfaction, acceptance and above all, purchase intentions in a highly competitive market [5]. In the study conducted by [10], purchase intention is explained and measured by consumers' behavioral intentions and willing-to-buy which are consequences of consumers' overall evaluation of a brands and information derived on social media platforms.

\subsection{Hypotheses development}

\subsubsection{The impact of UGC on functional and hedonic brand image}


Sequel to the increasing trend of adopting social media for sorting brand-related information, social media platform is increasingly becomes a platform for building brand image. This is because what consumers read on social media affect their judgments and perceptions about their association and nonfunctional attributes of brands. For instance, [11, 12,13] have found significant impact of UGC on either brand image or brand association. Subsequently, the following hypotheses are proposed;

H1: User-generated contents have positive impact on functional brand image

H2: User-generated contents have positive impact on hedonic brand image

\subsubsection{The relationship between functional, hedonic brand image and brand purchase intention}

Previous studies have implied that, consumers' perceptions of brand image leads to intention to purchase, purchase and permanent purchase of the same brand. Hence, consumers' perceptions that are generated through their judgments of both hedonic and functional attributes of a brand influence their attitudes and behaviors. This notion has been subjected to empirical tests in different context by previous researchers $[11,14,15,16,17]$. The implication of the findings from these previous studies is that, consumers; mindset and perception of brands enhance the process of making purchase decisions. In view of this, the following hypotheses are formulated;

H3: Functional brand image positively influence purchase intention

H4: Hedonic brand image positively influence purchase intention

\subsection{Conceptual Framework}

Fig 1 presents the conceptual framework that is proposed in this study. The framework depicts the relationships between UGC, functional and hedonic brand image and purchase intention.

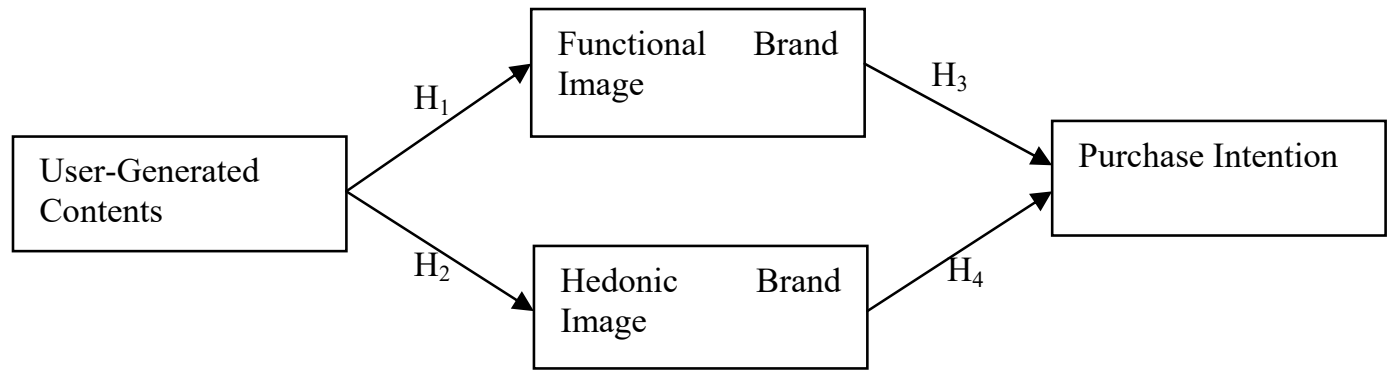

Fig. 1. Conceptual Framework

\section{Method and findings}

This study adopts a quantitative research method, using a survey research design. Data was gathered from an online survey conducted among followers of automotive brands (both PROTON and PERODUA) on Facebook. The link of online questionnaire was sent in form of personal messages to 300 followers of fan pages of the Malaysian automotive brands. The respondents are those that are actively involve on these fan pages in form of posting 
contents, commenting and sharing of contents. Out of the 300 that received the questionnaires, 117 answered to the questionnaire. 3 of the received questionnaires were invalid and the analysis is based on 114 respondents. The measurements for measuring the variables understudied in this research were adapted from previous studies. Items for measuring UGC were adapted from [1]. Items for measuring both functional brand image and hedonic brand image were adapted from [1] and [11]. Finally, items were adapted from [12] and [8] for measuring brand purchase intention. A five Likert type scales ranging from 1 "Strongly Disagree" to 5 "Strongly Agree". Certain preliminary statistical assumptions (such as; normality, outliers and linearity) were met before developing the measurement and structural models using PLS-SEM.

\subsection{Measurement Model}

Table 1 presents the result of the reliability and validity of the data. The findings demonstrate that composite reliability (CR) values of the construct have internal consistency [13]. Also, the values of average variance extracted (AVE) of the entire constructs are above 0.5 which is the minimum threshold value. This explains that, the constructs achieved an acceptable convergent validity [14]. Discriminant validity is achieved as presented in Table 2. The result shows the squared correlations for each construct as lesser than the average variance extracted by the indicators measuring that construct

Table 1. Internal Consistency and Convergent Validity

\begin{tabular}{|c|c|c|c|c|}
\hline Construct & Items & Loading & AVE & CR \\
\hline User-Generated Contents & UGC1 & 0.9056 & 0.691 & 0.8986 \\
& UGC2 & 0.8934 & & \\
\cline { 2 - 4 } & UGC3 & 0.7996 & & \\
& UGC4 & 0.7115 & & \\
\hline Functional Brand Image & FBI1 & 0.8291 & 0.7079 & 0.9061 \\
& FBI2 & 0.8775 & & \\
\cline { 2 - 3 } & FBI3 & 0.9017 & & \\
\cline { 2 - 3 } & FBI4 & 0.7491 & & \\
\hline Hedonic Brand Image & HBI1 & 0.7705 & 0.6268 & 0.8342 \\
& HBI2 & 0.7734 & & \\
\cline { 2 - 3 } & HBI3 & 0.8297 & & \\
\hline Brand Purchase Intention & BPI1 & 0.9337 & 0.8975 & 0.9633 \\
\cline { 2 - 3 } & BPI2 & 0.9627 & & \\
\cline { 2 - 3 } & BPI3 & 0.9454 & & \\
\hline
\end{tabular}

Table 2. Discriminant Validity

\begin{tabular}{|c|c|c|c|c|}
\hline & BPI & FBI & HBI & UGC \\
\hline BPI & $\mathbf{0 . 9 4 7}$ & & & \\
\hline FBI & 0.8603 & $\mathbf{0 . 8 4 1}$ & & \\
\hline HBI & 0.7695 & 0.6741 & $\mathbf{0 . 7 9 1}$ & \\
\hline UGC & 0.3203 & 0.2958 & 0.392 & $\mathbf{0 . 8 3 1}$ \\
\hline
\end{tabular}

Notes: The square root of the AVE are marked in italics. 


\subsection{Structural Model}

The proposed hypotheses were tested through the assessment of the structural model. Table 3 presents the result of the path coefficient and the decision for every hypothesis. The findings revealed that, all the hypotheses formulated in this study were significant (UGC $\rightarrow$ FBI, $\beta=0.2958, p<0.05$; UGC $\rightarrow$ HBI, $\beta=0.392, p<0.05$; FBI $\rightarrow$ BPI, $\beta=0.6261, p<$ 0.05 ; HBI $\rightarrow$ BPI, $\beta=0.3475, p<0.05$ ). In addition, the findings presented in Table 4 shows the values co-efficient of determination (R2), cross-validated redundancy (Q2) and effect size (f2) of exogenous constructs on endogenous constructs. The values of coefficient of determination shows that both functional brand image and hedonic brand image explain $80.6 \%$ variances in brand purchase intention. User-generated contents explain $08.7 \%$ of variances in functional brand image and $15.3 \%$ of variances in hedonic brand image. The Q2 values reported in Table 4 for brand purchase intention, 0.7157; functional brand image, 0.0616; and hedonic brand image, 0.0932 are all greater than 0 , which shows that the exogenous variables have predictive relevance over the endogenous variables [20]. Finally, f2 values explain the importance of each exogenous variables beyond the significance analyzed in Table 3 . Table 4 shows that the effect size of functional brand image is large while the effect of hedonic brand image is medium on brand purchase intention.

Table 3. Path Co-efficient Assessment

\begin{tabular}{|c|c|c|c|c|}
\hline Hypotheses & Direct Effect ( $\beta$ ) & Std. Error & T-Statistics & Decision \\
\hline UGC -> FBI & 0.2958 & 0.1243 & 2.3787 & Supported \\
\hline UGC $->$ HBI & 0.392 & 0.1176 & 3.3346 & Supported \\
\hline FBI -> BPI & 0.6261 & 0.0544 & 11.4984 & Supported \\
\hline HBI -> BPI & 0.3475 & 0.0492 & 7.0649 & Supported \\
\hline
\end{tabular}

Table 4. Determination of co-efficient $\left(\mathrm{R}^{2}\right)$, predictive relevance $\left(\mathrm{Q}^{2}\right)$ and effect size $\left(f^{2}\right)$

\begin{tabular}{|c|r|c|c|c|}
\hline & \multicolumn{1}{|c|}{$\mathbf{R}^{\mathbf{2}}$} & $\mathbf{Q}^{\mathbf{2}}$ & $\boldsymbol{f}^{\mathbf{2}}$ & Effect Size \\
\hline BPI & 0.806 & 0.7157 & & \\
\hline FBI & 0.0875 & 0.0616 & 1.0928 & Large \\
\hline HBI & 0.1536 & 0.0932 & 0.3351 & Medium \\
\hline
\end{tabular}

\section{Discussions and conclusions}

The findings of this study demonstrate the significance of user-generated contents on functional brand image and hedonic brand image. Also, the findings also reveal that, both functional and hedonic brand image have significant influence on brand purchase intention. The findings of this study provide an instructive insight for brand managers on the implications of social media communications and especially user-generated contents. This study provide an empirical justification to the notion that, the pervasiveness of social media as a strategic channel for marketing communication channel has enhanced consumers' connection and engagement with brands. Furthermore, consumers' anecdotal comments, experiences and thoughts of a brand have significant influence on other consumers attitude and perception of both functional and hedonic brand image [7] as well as purchase decisions. The finding of this study is consistent with the findings of previous researchers on the impact of social media users' brand-related contents on brand image and brand 
purchase intention [12]. The study offers a number theoretical contribution which include; the impact of UGC is higher on hedonic brand image than functional brand image. Meanwhile, the findings of this study indicate that, functional brand image influence purchase intention. More so, understanding the impact of UGC on brand equity has a practical importance, considering the level in which consumers are adopting social media platforms to search for brand related information [1].

This study however, has certain limitations that can guide future studies. In view of the nature and features of social media, being a platform that anchor all sorts of communication with numerous contents characteristics (promotion, advertisement and product information) and media type (text, video and photo), researchers should consider determining the differential impacts of these characteristics and media types on brand image. Furthermore, researchers are recommended to determining the impact of UGC and other types of social media contents on other dimensions of brand equity such as brand awareness, brand loyalty and brand preference.

\section{References}

1. M. Bruhn, V. Schoenmueller, and D. B. Schafer, Are social media replacing traditional media in terms of brand equity creation?. Manag. Res. Rev., 35, 9 (2012).

2. G. Christodoulides, C. Jevons, and J. Bonhomme. J. Advert. Res., 52, 1 (2012).

3. OECD, The Evolution of News and the Internet, (2010).

4. P. M. Homer, Perceived quality and image: When all is not 'rosy', J. Bus. Res., 61, 7 (2008).

5. J. Hanaysha and H. Hilman. J. Asian Bus. Strateg., 5, 7 (2015).

6. K. Goodrich, Anarchy of effects? Exploring attention to online advertising and multiple outcomes. Psychol. Mark., 28, 4 (2011).

7. S. Gensler, F. Völckner, Y. Liu-Thompkins, and C. Wiertz. J. Interact. Mark., 27, 4 (2013).

8. Y. Zhang. Open J. of Buss. and Manag. 3, 1 (2015).

9. A. J., Kim, and E. Ko. J. of Busi. Rese., 65, 10 (2012).

10. S. M., Broniarczyk, and A. D. Gershoff. J. of Mark. Rese., 40, 2 (2003).

11. B.,Yoo, and N. Donthu. J. of Busi Rese., 52, 1 (2001).

12. D. Gefen, D. Straub, M. Boudreau, Structural equation modeling techniques and regression: guidelines for research practice. Commun. Assoc Inform. Syst., 7, (2000).

13. J. F., Hair G. T.M., Hult, C. M., Ringle, M. Sarstedt, A primer on partial least squares structural equation modeling (PLS-SEM). Sage Publications, Thousand Oaks. (2014).

14. C. Fornell, J. Cha, Partial Least Squares. In: Bagozzi RP (ed) Advanced methods of marketing research. Blackwell, Cambridge, (1994). 